\title{
Collaboration and Resource Sharing in Engineering Education
}

\author{
http://dx.doi.org/10.3991/ijep.v3iS1.2412 \\ James Uhomoibhi \\ University of Ulster, Northern Ireland, UK
}

\begin{abstract}
In present day's world of globalisation, institutions are not only fostering the formation of graduates able to operate in one location or country but desires to produce the global engineer equipped with the right knowledge and skills able to operate in any part of the world. A lot of online resources have been developed and are made freely available on the World Wide Web (web). Some of these have been developed by individuals, institutions and business organisations with an aim to engage learners and users and in aid of helping them improve their productivity and use of these tools either for personal or workplace benefit. This paper examines some of the resources for sharing and collaboration in engineering education investigating the prospect and challenges and influence of online technologies. We examine the influence of culture and impact of languages with a focus on Africa. In recognition of the challenges and potential for positive contribution to improved learning, economy and life in general, we conclude that it is paramount that opportunities created by modern technologies be explored and exploited through sharing and collaboration for enhanced engineering education provision in Africa.
\end{abstract}

Index Terms-Resource sharing, collaboration, engineering education, e-learning, sustainable development.

\section{INTRODUCTION}

Computing and the web have changed the mode of teaching and learning and the mode of education provision. This paper critically examines and reports on the prospects and challenges facing engineering education with respect to learning, teaching and research. The advent of online technologies has meant access to hitherto remote information for the learners and oftentimes teachers and researcher who are geographically dispersed. In the case of Africa there are still challenges to be addressed such as the lack of power for ICT equipment the high cost of purchase and maintenance of these infrastructures, inadequate knowledge and skill base for sustaining and maintaining these devices [1]. It was the introduction of the mobile telephones that revolutionised the mode of interaction and communication amongst all section of society to include, the local government, the businesses and most importantly the education sector. Africa has not allowed itself to be left behind in the scheme of things when it comes to use of available technologies to which they have access. Hence today we see the innovative use of mobile phones by teachers and students in Africa in access information. Smart phones are now being used to access open education resources (OER) by different classes of learners to advance themselves.
The internet has made it possible for individuals and organisations to communicate effectively and engage in sharing resources for enhanced learning and productivity. With increased access to education there is increased competition for resources. Consortia, institutions and research alliances have been developed to address some of the challenges faced by users. In Africa, where there is a lack of infrastructure, a support mechanism would have to be developed to ensure high quality research and education. It is important to develop these systems using available tools which today remains largely mobile devices accessible online via e-learning.

There are questions to which answers should be sought in order to address issues of resource sharing and collaboration in engineering especially as it applies to the African continent, viz: What is education, culture and technology? What is the significance of links between science, technology, engineering and mathematics (STEM) education and sharing for development? What role, if any and potential has technology especially computing and information technology (IT) on society? What makes for sustainable development in the face of globalisation and current world economic crisis? What does the future hold for Africa in the face of globalisation? The world has been made small. It is easy to see, telephone, network and communicate with anyone anytime anywhere. The internet has made everyone equal players on a "global" stage.

Education involves the systematic training and instruction, the imparting of knowledge and abilities and the development of character and mental powers. Culture is used to describe advanced development of human powers, the development of body, mind and spirit by training and experience. It is the evidence of intellectual development in human society encompassing all the arts, beliefs, social institutions which characterises a community, race of group. By the term technology, for the purpose of this paper, we mean a study, mastery and utilization of manufacturing and industrial methods, a systematic application of knowledge to practical tasks at in industry, at work and at home. The system of engineering education varies from country to country. In Africa depending this is largely dependent on history and colonial past of any given country. We draw specifically here on the system of education implemented in Nigeria.

\section{A. National Education Systems}

Africa is the world's second largest and second most populous continent, after Asia. In terms of size, Africa is about 30.2 million $\mathrm{km}^{2}$ (11.7 million sq mi) including adjacent islands; it covers $6 \%$ of the Earth's total surface area and $20.4 \%$ of the total land area. With about 1 billion people (as of 2009) in 61 territories, it accounts for about 
$14.72 \%$ of the world's human population. Africa is a resource-rich continent but all its countries are still classified as developing nations or emerging economies. In particular, Nigeria is the most populous country in Africa and seventh most populous country in the world. It is the most populous country in the world in which the majority of the population is black. Nigeria is listed among the "Next Eleven" economies, and is a member of the Commonwealth of Nation. Its economy is one of the fastest growing in the world. In 2008, 2009 and 2011, IMF projected growth of $9 \%, 8.3 \%$ and $8 \%$ respectively. Nigeria is a strong economic force driving the African economy. With a population of more than 150 million and a land area of about $923768 \mathrm{~km}^{2}$ (32nd largest country of the world), the country believes in the development of the best economic, social and education services to improve the lives of its people.

The national education system in Nigeria is a three-tier one comprising a primary, secondary and tertiary system. The tertiary education comprise of specialist teacher training colleges, polytechnics and universities. The teacher training colleges of Education, offers a 3-year course of study (post senior secondary education), leading to the award of the Nigeria Certificate in Education (NCE). They train teachers for the basic and secondary schools and adult literacy programs. The polytechnics are largely technical colleges, offering at the first instance, a 2-year course of study (post senior secondary education), leading to the award of the National Diploma (ND). Holders of the ND may proceed to a further 2-year course of study (after a compulsory one-year industrial training), leading to the award of the Higher National Diploma (HND). Polytechnics were established primarily to train middle level manpower in largely technical fields of study. The proprietorship of both the colleges of education and the polytechnics include state and federal governments and the private sector. Universities offer a standard 4-year course of study, post senior secondary education (5 or 6 years for some professional courses), and leading to the award of the Bachelor's, master's and doctorate degrees. There may be enhanced placement for holders of advanced qualifications.

The proprietorship of universities varies for different countries. In Nigeria this has had varied from the establishment of the first University College Ibadan (of the University of London) owned exclusively by the federal government. Between 1960 and 1970, regional governments established their own universities and from 1970, the federal government took over the running of the regional universities. Thus, between 1970 and 1979 university education was the exclusive responsibility of the federal government. It was in the 1979 constitution once again state government were allowed to establish state government owned universities. In 1999, the first ever private universities were licensed and as at today, there are a total of 116 universities in Nigeria, comprising 36 federal, 35 state and 45 private universities. The Main and central agency involved with the regulation and accreditation of university education in Nigeria is National Universities Commission (NUC). This is often done jointly with responsible Professional bodies governing specific disciplines or areas of specialization like physics, engineering, etc. . The NUC is the sole regulatory agency for university education in Nigeria, established in 1962 as an advisory agency on university education in the Cabinet
Office. Higher education institutions in any country play the role of core actors for knowledge creation. They help in the education and training of new experts. Higher education institutions facilitate the production of new human capital by amount of talents and in the building up of social capital, human connections and interaction. They affect the cultural life and enrich the quality of society.

\section{B. Sharing and Collaboration in Engineering Education}

Engineering education involves development and deployment of learning which could involve the use of real and virtual systems utilizing both intranet and internet. Many systems exist but the basic tools which allow both the passive and active learners to access and interact with instructional materials, peers and tutors through the use of a simple browsers in a windows or similar operating system environment. Sharing and collaboration does not involve only accessing information on a repository. We use sharing to describe the process where users could access and use same resource (an application) for teaching, learning and cooperation purposes over network connections. There should exist a familiar and easy-to-use graphical user interface like the common browsers without the problems of bandwidth. The system for sharing and collaboration should be platform and browser independent, with the ability to extend its use to a range of applications in science and engineering education.

The demands of society and the policies of the government are vital factors promoting the collaboration and resource sharing in any society. The channels for these collaborations amongst others comprise exchanges, such as academic meetings, ex-change visits and research papers to include co-authoring etc. All of which allows permits the sharing of resources with each other. Some of the most successful collaboration and resource sharing initiatives in the area of iLab does include those of MIT with ISA, FEUP and others from Brazil [1, 2]. The African Virtual University and iLab Africa Network nodes located in Nigeria, Uganda, Tanzania and South Africa are set to escalate to the next level the development of virtual laboratory resource sharing as the laboratories fully develop and advance.

\section{STEM EDUCATION AND SUSTAINABLE DEVELOPMENT}

Science Technology Engineering and Mathematics (STEM) professionals including business and engineering educators (involved in teaching, learning and research) in particular play a large role in helping to improve the standard of living and maintaining the competitive edge serving as an advantage in the present internationally economically competitive world. STEM graduates are needed in the world and more so in Africa to develop new technologies to help all people in the continent achieve a better quality of life. They are to specifically, supply the intellectual talent for the development of the new technologies that will be needed to both feed the increasing population and solve the many environmental problems confronting both developed and emerging nations [3]. It has been shown that that most high school teachers, many adults, including science and mathematics teachers, are not knowledgeable about what engineers do [4, 5]. Engineering literacy is important at all levels and the resources to facilitate the education of the cohort of students, the pre-service and in-service teachers should be provided for to addresses the many issues and resolve problems facing 
engineering education. The problem is highlighted further where there is total lack of the will to engage in collaboration and sharing some of these resources even when the technology is there to make it happen.

\section{A. Availability and Identification of Resources}

A Plethora of engineering education resources are available online to facilitate the teaching learning and research of general and specific areas and problems. Some of these are have been made available by individuals, institutions such as MIT in the United States, the OU in the UK, FEUP in Portugal, to mention but a few. In this paper we cite a few of these and their websites where most of these open education resources (oer) are available. Africa is the world's second largest and second most populous continent, after Asia. about 30.2 million $\mathrm{km}^{2}$ (11.7 million sq mi) including adjacent islands, it covers $6 \%$ of the Earth's total surface area and $20.4 \%$ of the total land area. With about 1 billion people (as of 2009) in 61 territories, it accounts for about $14.72 \%$ of the world's human population Africa is a resource-rich continent but all its countries are still classified as developing nations or emerging economies. It is important that we recognise the challenges facing the development and delivery of engineering education in Africa. Some of these challenges have been reported $[1,6,7]$.

\section{B. Technology Impact and Development of Engineering Teaching and Research Resources}

Technology has been responsible for the many happenings (good and otherwise) in the field of knowledge advancements and skills acquisition. However there exist gaps and digital divide [8], which need to be addressed if the 21st century is to realise any of the United Nations Millennium Development Goals (MDGs) that have been set, some of which are earmarked to be achieved by 2015 . Engineering Education Providers (academics and institutions) owe it to learners to collaborate, cooperate and work towards the enhancing provision. It is important that communication tools (most of which are freely available) and web 2.0 technologies are brought to bear in furthering the cause of engineering education and research. The iLab (remote and virtual laboratories) initiatives are worthy examples that have the potential to deliver for both the learners and the educators. A learning culture has to be developed and a common language put in place to promote understanding and widen participation of collaborating partners from Europe, Africa, USA and the rest of the world.

A plethora of resources for engineering teaching and learning exist online. Examples of websites where most of them are available include sourceforge, tucows (http://www.tucows.com), commonwealth of learning (http://www.col.org/Pages/default.aspx), 101 Web 2.0 Teaching Tools (http://oedb.org/library/features/101-web20-teaching-tools), etc. Some of these online tools and resources continue to make teaching and learning easier. Students are able to collaborate and save time. It makes it easy for the practitioners and learners to be organised whilst facilitating access at anytime anywhere.

\section{Relevance, Currency and the Process of Sharing}

Where there is the absence of the right type of infrastructure, the technological knowhow and policies to begin to effect change, it becomes an uphill task to engage in any process that can bring about change. Sharing is a part of communication because both the giver and the receiver have come to know how important the resource (tangible or intangible) being exchanged is useful. Sharing is a process that could be formal and informal. It takes for the right condition to be established to facilitate this process. In a technologically driven and networked world we now live in, 21st century world of globalisation, a society without access to computers, the World Wide Web and the internet, and the ability to communicate using presently available technology, will be left behind, the communities would feel distant and isolated and starvation, poverty and underdevelopment would become the order of the day. The issue of hopelessness sets in when the governance structure, policies and education provision either is non-existent, obsolete or inadequate through failures to meet the fundamental needs of individuals and communities. It takes engineering to plough through the process of providing the right type of products and processes for improvement of life and society. It takes education equipped with appropriate resources to produce the right type of engineers. Communication is vital and an important ingredient for the health and wellbeing of people and communities. In Africa, it was only after the introduction of the mobile phones, less than a decade ago, that individuals and businesses found it possible to communicate regularly. In addition today, there are still issues with accessibility (provision of effective and efficient means of transport), regular supply of electricity and encouragement of education, public and business experts to communicate and share through sharing information, production of reports, distribution of publications and engagements in collaborations with the sectors.

\section{SIGNIFICANCE AND SUPPORT FOR SHARING}

\section{A. Broad band and Connectivity}

Though the internet has helped to facilitate access to information and enabled sharing of resources, it has been tempered with several problems and challenges resulting mainly from fault-prone undersea cable. The launch of a new satellite, HYLAS 2 satellite, developed by Avanti Communications, based in London, deployed in early August from the European spaceport in Kourou, French Guiana, South America is set to usher in some new positive changes. The satellite completed its orbital testing in early September and is now almost ready to begin commercial services [9]. This is set to revolutionise broadband in East and Southern Africa, helping to bring high-speed internet to some of the millions in the region enabling uninterrupted sharing of information and collaboration without the hitherto repeated outages experienced over the years.

The significance of recent developments has let to new approaches to engineering education and the use of collaborative cross-cultural project work for learning across continents, cultures, languages and time zones. Teachers and learners begin to seek situation-based understanding and analysis of information, disassembling of problems with no initial solutions. Visualization and presentation of data are utilized where recourse is made of ability to make creative and interactive presentations of complex data to increase understanding. 


\section{B. Funding and Support for Initiatives}

Research and development (R\&D) is what drives progress of organisations, business communities and society. The value of history is to correct the mistakes of our predecessors. It has been shown that engineering is responsible for majority of the advances made in the developed nations of today. If Africa is to compete as it should, it has to demonstrate its willingness and ability to recognise, acknowledge, accept the need for funding and support for engineering initiatives and for engineering education and research. Seeing how engineering businesses have transformed communities in the developed world of today, Africa has to invest in research and development, fund and support engineering education initiatives targeted at relevant projects for sustainable development. Most of what exist in the system today is focused on subsistence, combating hunger, sickness and diseases, poverty and ill-judged management styles or structure. The author calls for investment in education and a drive to engage with the processes derived thence to address some of the aforementioned challenges which societies face time and time again. Engineering Education practitioners in Europe, USA, South America, Japan etc have indicated through the provision of OER (open education resources) and associated teaching and learning resources their willingness and preparedness to share and collaborate with individual and institutions in Africa. Such collaborations are bound to be mutually beneficial to all parties and are well placed to contribute to achieving aspects of the United Nations Millennium Development Goals (MDGs), that summed up the eight ways to change the world touching on extreme poverty, primary education, gender equality, child mortality, maternal health, HIV/AIDS, environmental sustainability and developing global partnership. Underpinning success with these goals is infrastructure. Six of the eight MDGs are directly related to human condition, that is, health, economic and social well-being, enabling the individual to play a useful role in the world. The key to sustainable development in Africa is the creation of infrastructure, real infrastructure that delivers actual pro-poor outcomes. Research shows that African economies, if they are to develop need access to ample, reliable and affordable energy. The lack of energy and security feeds into a cycle of poverty. It has been reported that $60 \%$ of Africa's population lack access to electricity $[1,10]$.

\section{Resource Sharing, Collaboration and Sustainable Development}

The prerequisites for development include reasonable governance structures, a functioning civil society, an effective local economy and freedom from persecution, conflict and corruption. A functioning society an business depends on a series of complex infrastructure networks, providing cities and towns with clean water, transport, energy and capacity to trade efficiently. Effective economic recovery and sustainable development also depends on extending infrastructure to those in the world who have been left behind in the past years and who will be exposed to even greater threats in the next decades of years ahead $[10,11,12]$. The world today is gradually slipping into a state of environmental catastrophe with a backdrop of 1 billion people without access to safe water, 1.6 billion without electricity, 1 billion without telephone services, 1 billion without all-weather roads and 2.5 billion without safe sanitation. The two most important issues appears to be centred around poverty and climate change where efforts would have to be concentrated on engineering the poor out of poverty and misery and from energy and environmental crisis and with global climate at a tipping point. The eight millennium development goals of the United Nations (UN) touch on extreme poverty, primary education, gender equality, reducing child mortality, improvement of maternal health, dealing with HIV/AIDS, working on attaining environmental sustainability and developing global partnership. In this era of global economic crisis, the challenges of the 21st century are identified to include population growth, increase in urbanisation, food security, poverty alleviation, energy and water demand, climate change, counter terrorism, biodiversity and infectious diseases. Several initiatives continue to be developed and deployed to help facilitate sharing and collaboration. Examples of some of these include the engineers' toolkits for developing world launched in London on 19 October 2010 and in Ghana on 19 April 2011 [10] for which further details are available at http://www.ice.org.uk/patoolkit and iLab Africa Network established during the EDUCON-2012 International Conference held in Marrakesh Morocco on 19 April 2012. Through sharing these freely openly available resources and collaboration with others both within and across continents it is believed that progress can be made in promoting access to education and enhance teaching, learning and research.

\section{INFLUENCE OF LANGUAGE, CULTURE, COMMUNICATION AND EDUCATION}

Culture of Competition in a profit-driven economy is an important factor worth considering. Everything has a price and cost is attached to knowledge. The pricing of knowledge is seen as most important at times to the disadvantage of learners and learning. Culture is a set of learned beliefs, values, attitudes, habits and forms of behaviour that are shared by a society, and are transmitted from generation to generation within that society. Learning is a process that can comprise all, some, or one of three steps: inventing an original solution to a problem, or thinking; committing a solution to memory, or memorizing; becoming efficient at applying the solution to a problem, or forming a habit. Learning' is a function of such factors as relative advantage, compatibility, complexity and divisibility and communicability. Research has shown that the most direct influence on learning is the social group to which the learner belongs, that is the family and social class, which in turn influences the culture of the group and society. We distinguish between civilized and primitive cultures and between cultures of advanced and those of developing nations. Technology has and continues to play a significant role in how cultures and peoples are perceived.

The problems and constraints facing technology are many and varied. There are the issues of climate change, lack of affordable electricity that is sustainable. There is insufficient capital resources and investment in technology with increasing unemployment rate, lack of skilled personnel and poor system of education system, health facilities and poor methods for agricultural produce. At a more serious level, there is what could be perceived as lack of proper policies and strategies with inadequate and uneven distribution of infrastructure. There is a lack of 
private sector involvement and designing technology suitable for poor people. The tax regulation is poor and there appears be no adequate, reliable and affordable power supply and lack of human resource capacity. Technology however continues to impact economic growth, education, transport industry, communication, employment, health and systems of banking and communication.

Language and the Culture of community is related to sharing and common good. The philosophy of open source seems to support this practice. Competition is encouraged but at a level to facilitate both personal and professional development in an open environment to improve a common product or process for either private or public use.

The impact of language in the context of education development and implementation is huge. The engineering education provision in Africa is largely dictated by the official language adopted by the government. In most countries this can be English, Portuguese, French, Italian, Spanish etc. This is in addition to the traditional language of the tribe or community. Studies have shown that language interpretation and application plays crucial role in learning. In a bit to collaborate language remains the communication tool without which cooperation and understanding cannot be achieved. The different disciplines have developed their own specific languages used for communication to foster understanding of concepts. In the course of the present research it has been found that there is a plethora of freely available resources in the principal languages spoken and used in the areas. The availability of technology and the web, equipped with the software tools for interpreting and translating from one language to another continue to help meet the need of learners engaged in the education process .

\section{A. International Professional Organisations and Businesses}

In Africa there exist a number of professional bodies that regulate practices in these countries. Unlike in Europe, Unites States of America or countries like the United Kingdom it is a challenging to find or identify the one professional body at a continent level acting on behalf of practitioners throughout the Africa. There may be such organisations as COREN in Nigeria, the African Laser Centre (ALC) with its headquarters in South Africa, the Engineering Council of South Africa (ECSA). It is difficult to compare or match their work with those of SEFI (European Society for Engineering Education), IET (UK Institution for Engineering and Technology), IoP (UK Institute of Physics), BCS, The Chartered Institute for IT etc. Only in recent times has there been an attempt to set up the AfPs (African Physical Society) launched in 2009 in Senegal. Most of the activities are still being developed. The efforts of the ALC must be recognised. Since its formal inception in 2005, it has and continues to offer support (research grants and scholarships) to scientists from all over Africa with which to engage in research and scholarly activities either in recipients' home countries or at locations where facilities are available to do so in areas of science, engineering and technology using lasers.

\section{CONCLUSION}

Learning can be perceived as a cultural practice, a process, for which tools are required to analyse and under- stand. The Internet and present mobile technologies have made it possible for us to understand similarities and differences better compared to situations before now. Globalisation has had a firm influence on how universities in different countries are packaging learning and on how businesses are taking decisions on what skills they require and how well what work is done. All of these go to facilitate economic growth which over the past few years have been seen to being a problem globally (global economic crisis).

There are so many factors that are important ingredients which contribute to enhanced learning. In Africa, some of these ingredients include language, students' relation to the dominant culture and motivational state of the learner. The structuring of knowledge; the role of social interaction; mediating experiences and devices and the institutional meaning attached to learning are also strong contributors. There are instances where the culture of learning may differ. The problem of defining the difference remains crucial and vital to be resolved. Through sharing and learning systems are improved for global collaborative and beneficial projects.

It is important that a joined-up thinking and a collaborative approach is adopted in engineering education to ensure that the goal of global engineering education is achieved. There are some noteworthy funding initiatives, projects and support mechanisms in Europe (Erasmus Mundus,), USA (Atlantis, USAF) and Africa (ALC) which could be explored using freely available tools and resources to develop curriculum and network infrastructures needed to enhance sharing and collaboration. Some questions remain to be answered. Could it be that Africa has something to offer the world in addressing some of the challenges we face today (economically, socially and educationally)? Would sharing resources and collaborating with African engineering education colleagues facilitate a process for teasing out solutions to some of the identified problems, some of which have been highlighted? Some if not all of these are subjects of further research in future. We believe that sharing is important. Communication and collaboration are keys to unlocking the door to progress and success. The present efforts to collaborate and share resources for improving engineering education provision are laudable and are on course steadily to success.

\section{REFERENCES}

[1] Damasen I. Paul, James Uhomoibhi, (2012) "Solar power generation for ICT and sustainable development in emerging economies", Campus-Wide Information Systems, Vol. 29 Iss: 4, pp.213 - 225 http://dx.doi.org/10.1108/10650741211253813

[2] J.O. Uhomoibhi, J.Palma, P.Alves, T.M. Restivo, M.R. Piteira, F.O. Soares and C. Fernandes (2011), Development of E-Learning in Higher Education and Future Directions, in Innovations 2011 World Innovations in Engineering Education and Research by Aung W et al (Eds), iNEER, USA, pp 35-49, ISBN: 978-09818868-2-4

[3] Robinson M and Kenny B, "Engineering Literacy in High School Students” Bulletin of Science, Technology \& Society, Vol. 23, No. 2, April 2003, 95-101 http://dx.doi.org/10.1177/0270467603 251300

[4] Robinson, M., Fadali, M., Carr, J., \& Maddux, C. (1999, November). Engineering principles for high school students (Session 13a7). Proceedings of the 1999 Frontiers in Education Conference. Available from http://fie.engrng.pitt.edu/fie99 


\section{COLLABORATION AND RESOURCE SHARING IN ENGINEERING EDUCATION}

[5] Robinson, M.,\&Maddux, C. (1999, October). What do secondary science and mathematics teachers know about engineering? Bulletin of Science, Technology \& Science, 19(5), 394-402.

[6] PAO Adegbuyi and J Uhomoibhi (2008), 'Trends in the development of technology and engineering education in emerging economies', Multicultural Technology and Education Journal, Vol. 2, Issue 3, pp 132 - 139 http://dx.doi.org/10.1108/ 17504970810900432

[7] M O Aburime and J O Uhomoibhi (2010), "Impact of technology and culture on home economics and nutrition science education in developing countries”, Multicultural Education and Technology Journal, Vol. 4, Number 1, pp. 4-16 http://dx.doi.org/10.1108/ 17504971011034692

[8] J Uhomoibhi (2006), 'Digital Divide and Education' in Innovations 2006 - World Innovations in Engineering Education and Research by Aung W et al (Eds), iNEER, USA, pp 467-480, ISBN: 0-9741252-5-3

[9] Curtis Abraham, 2012, "Satellite broadband gets millions more Africans online”, New Scientist available at http://www.newscientist.com/article/mg21628866.100-satellitebroadband-gets-millions-more-africans-online.html (accessed September 2012)
[10] Jowitt P (2011), "Infrastructure Delivery for International Development”, ICEE-2011, International Conference on Engineering Education, 21-26 August 2011, Belfast, UK. [Keynote]

[11] R Alexander, E Badenhorst and T Gibbs, (2005), "Intervention programme: a supported learning programme for educationally disadvantaged students”, Medical Teacher, Vol. 27 Issue 1, pp 66 - 70 http://dx.doi.org/10.1080/01421590400016472

[12] A. Arlene, (2005), "Access and resistance: challenges of using on-line environments to teach academic discursive practices", Education as Change, Vol. 9, Issue 2 pp 74

\section{AUTHORS}

J. O. Uhomoibhi is with the University of Ulster, Northern Ireland, BT37 0QB, UK. (e-mail: j.uhomoibhi@ulster.ac.uk).

This article is an extended and modified version of a paper presented at the IGIP2012 conference, held 26 - 28 September 2012, in Villach, Austria. Received 01 December 2012. Published as resubmitted by the authors 28 January 2013. 